\title{
Energy estimates of relaxation and creep deformation processes of polymeric materials
}

\author{
A. Makarov \\ Vice-Rector of Science, Saint Petersburg State University of Industrial Technologies and Design, Saint \\ Petersburg, Russia
}

\section{A. Demidov}

Rector, Saint Petersburg State University of Industrial Technologies and Design, Saint Petersburg, Russia

N. Pereborova

PhD, Associate Professor, Associate Professor of the Department of Intelligent Systems and Information Security Saint Petersburg State University of Industrial Technologies and Design, Saint Petersburg, Russia

\section{Egorova}

PhD, Associate Professor, Associate Professor of the Department of Intelligent Systems and Information Security Saint Petersburg State University of Industrial Technologies and Design, Saint Petersburg, Russia

\begin{abstract}
The article considers energy estimates of nonlinear hereditary relaxation and creep processes. Polymeric materials have pronounced rheological properties including the flexible-chain structure of macromolecules that are in an oriented state and have an amorphous-crystalline structure at the supramolecular level (Pereborova et al., 2020a). According to the current views of structural physicists, at this level, the rheological properties of polymers, as a combination of elasticity, viscoelasticity and plasticity, are formed (Pereborova et al., 2020b). The decomposition of the total deformation value into the corresponding three parts is considered to be a difficult task due to their simultaneous occurrence and further development. Information about the complex pattern of distribution of material particles over relaxation and delay times can be obtained only through a physically-based analytical description of polymeric materials rheology in combination with the measurement of various deformation processes (Pereborova et al., 2020c). The accumulated experience of working with polymeric materials shows that the viscoelastic and plastic components of their deformation depend in a certain way on the level of applied mechanical action (Pereborova et al., 2020d). Hence, it follows that one creep or relaxation curve cannot be used to get any information on the delay or relaxation times (Pereborova et al., 2018a).
\end{abstract}

\section{THE METHODS FOR DETERMINING THE ACTIVATION ENERGY OF RELAXATION AND CREEP DEFORMATION PROCESSES OF POLYMERIC MATERIALS}

The main deformation processes of polymeric materials are relaxation and creep. To determine the activation energy of deformation processes, it is necessary to develop their mathematical models. The parameters of these processes, the relaxation and delay (creep) times, implicitly contain information about energy (Makarov et al., 2018a).

The physical meaning of the relaxation and delay time is the minimum time of conformational transition during which the assumed 'relaxing' or 'delaying' particle passes from one energy state to another overcoming some potential energy barrier (Pereborova et al., 2019a). 
The authors proposed mathematical models of relaxation and creep processes based on the Cauchy probability distribution of the relaxation and delay times. It is physically feasible as this distribution has an additivity property, i.e. the sum of random variables distributed according to the Cauchy law, is also distributed according to this law (Pereborova et al., 2018b).

To illustrate the above-noted statement, it is proposed to consider a woven polymer fabric which consists of threads made up of fibres. Experimental studies confirm that complex (composite) polymeric materials behave in a similar way in the relaxation and creep processes and these processes can be described by the same mathematical models (Makarov et al., 2016).

The second convenience of the Cauchy probability distribution is in its close similarity to the normal distribution on the basis of which many physical principles can be described.

And finally, the third advantage of the Cauchy distribution is that its cumulative distribution function is an elementary function normalized arctangent (Makarov et al., 2015).

$$
\varphi_{t}=\frac{1}{2}+\frac{1}{\pi} \operatorname{arctg}\left(\frac{1}{b} \ln \frac{t}{t_{1}}\right)
$$

in contrast to the probability integral for the normal distribution.

Here, the dimensionless logarithmic time is taken as an argument $\frac{t}{t_{1}}\left(t_{1}\right.$ - some value of base time), $b$ - the coefficient of the intensity of relaxation or creep processes.

The elementary character of this function considerably simplifies the rearrangement in mathematical modelling of relaxation and creep.

The simplest model of the relaxation process for the case of constant deformation $\varepsilon=$ const is given by (Pereborova et al., 2018c)

$$
E_{\varepsilon t}=E_{0}-\left(E_{0}-E_{\infty}\right) \varphi_{\varepsilon t}
$$

where $E_{0}$ and $E_{\infty}$ - asymptotic values of the relaxation modulus

$E_{\varepsilon t}=\frac{\sigma_{t}}{\varepsilon}, \sigma_{t}$ - time varying $\mathrm{t}$ stress.

Similarly, the simplest model of the creep process for the case of constant stress $\sigma=$ const is given by (Makarov et al., 2018b).

$$
D_{\sigma t}=D_{0}+\left(D_{\infty}-D_{0}\right) \varphi_{\sigma t}
$$

where $D_{0}$ and $D_{\infty}$ - aasymptotic compliance values $D_{\sigma t}=\frac{\varepsilon_{t}}{\sigma}$.

The simplest mathematical model of relaxation (1), (2) has an important advantage over other similar models as it has the smallest possible number of physically based parameters: three constants $\left(E_{0}, E_{\infty}, b_{\varepsilon}\right)$ and deformation-time function

$$
f_{\tau_{\varepsilon}}=\ln \frac{t_{1}}{\tau_{\varepsilon}}
$$

characterising the relaxation times $\tau_{\varepsilon}$ (Pereborova et al., 2019d).

The same can be said about the mathematical model of creep (1), (3). It also contains three physically based constants $\left(D_{0}, D_{\infty}, b_{\sigma}\right)$ and force-time function

$$
f_{\tau_{\sigma}}=\ln \frac{t_{1}}{\tau_{\sigma}}
$$

characterising the delay times $\tau_{\sigma}$ (Rymkevich et al., 2013)

Sufficient reliability and technical convenience follows from the analysis of the applicability of the considered simplest mathematical models of relaxation and creep used for the analytical description of the rheological properties of polymeric materials and the subsequently calculated prediction of loaded or deformable states of these materials. Due to the smallest number of 
parameters-characteristics, the simplicity of their determination from short-term experiments, and clarity of their physical interpretation, the developed methods seem to be promising not only for polymers but also for a number of other solid materials (Pereborova et al., 2019c).

The simplest mathematical models of relaxation (1), (2) and creep (1), (3) can be easily generalised for the case of complex relaxation $(\varepsilon \neq$ const $)$ and complex deformation $(\sigma \neq c o n s t)$ processes by using the Boltzmann-Volterra integral constitutive relations whose integral kernels are derivatives of the relaxation function or the delay function, respectively (Pereborova et al., 2018d). The mathematical model of a complex relaxation process is given by (Pereborova et al., 2018e),

$$
\sigma_{t}=E_{0} \varepsilon_{t}-\left(E_{0}-E_{\infty}\right) \cdot \int_{0}^{t} \varepsilon_{\theta} \cdot \varphi_{\varepsilon ; t-\theta}^{\prime} d \theta
$$

where $\varphi_{\varepsilon t}^{\prime \leftarrow}$ - relaxation kernel:

$$
\begin{gathered}
\varphi_{\varepsilon t}^{\prime}=\frac{\partial \varphi_{\varepsilon t}}{\partial t}=\frac{1}{\pi} \cdot \frac{1}{b_{\varepsilon}} \cdot \frac{1}{1+W_{\varepsilon t}^{2}} \cdot \frac{1}{t}, \\
\varphi_{\varepsilon t}=\frac{1}{2}+\frac{1}{\pi} \cdot \operatorname{arctg}\left(W_{\varepsilon t}\right) \\
W_{\varepsilon t}=\frac{1}{b_{\varepsilon}} \cdot \ln \frac{t}{\tau_{\varepsilon}}=\frac{1}{b_{\varepsilon}} \cdot\left(\ln \frac{t}{t_{1}}+\ln \frac{t_{1}}{\tau_{\varepsilon}}\right)
\end{gathered}
$$

Similarly, the mathematical model of a complex deformation process is given by (Gorshkov et al., 2013)

$$
\varepsilon_{t}=D_{0} \sigma_{t}-\left(D_{\infty}-D_{0}\right) \cdot \int_{0}^{t} \sigma_{\theta} \cdot \varphi_{\sigma ; t-\theta}^{\prime} d \theta
$$

where $\varphi_{\sigma t}^{\prime}$ - delay kernel:

$$
\begin{gathered}
\varphi_{\sigma t}^{\prime}=\frac{\partial \varphi_{\sigma t}}{\partial t}=\frac{1}{\pi} \cdot \frac{1}{b_{\sigma}} \cdot \frac{1}{1+W_{\sigma t}^{2}} \cdot \frac{1}{t} \\
\varphi_{\sigma t}=\frac{1}{2}+\frac{1}{\pi} \cdot \operatorname{arctg}\left(W_{\sigma t}\right), \\
W_{\sigma t}=\frac{1}{b_{\sigma}} \cdot \ln \frac{t}{\tau_{\sigma}}=\frac{1}{b_{\sigma}} \cdot\left(\ln \frac{t}{t_{1}}+\ln \frac{t_{1}}{\tau_{\sigma}}\right)
\end{gathered}
$$

At the same time, the set of assumptions on which these mathematical models are built should be considered. First of all, the governing equations (6) and (10) of the elastic-hereditary type have a phenomenological origin (Makarov et al., 2017a). Despite the achieved success in the modelling of elastic-hereditary and more general rheological media with a stable structure, it seems to be obvious that almost any mathematical model greatly simplifies the properties of a polymer material (Demidov et al., 2017). The essence of the alternativeness of two consistent equations of nonlinear hereditary viscoelasticity (6) and (10) is in the simultaneous use of two analogies, which are deformation-time (in the case of relaxation) and force-time (in the case of creep) (Makarov et al., 2017b). There are no direct contradictions to modern kinetic views in this approach. Although, it is unusual to simultaneously use two contradicting analogies at once. The approximate nature of both analogies can be the only physical justification of this approach (Makarov et al., 2015a). 
The accepted hypothesis about the feasibility of simultaneous consistent use of two logarithmically symmetric delay and relaxation kernels has an approximate nature and makes all sorts of calculation procedures easier because of a noticeable reduction in the number of parameters-characteristics. The question of preference of one kernel over another remains unclear and is subject to further research. The possibility of considering at least one of these kernels logarithmically symmetric is also not obvious (Makarov et al., 2015b).

In addition to the reduction of the number of parameters-characteristics, the simplest version of generalisation by introducing force-time and deformation-time analogies into the hereditary kernels in the normalized version plays a pivotal role.

The obtained force function of the delay times (5) and the deformation function of the relaxation times (4) in general qualitatively correspond to the modern approaches to kinetic thermofluctuation nature of 'behaviour' of the oriented amorphous-crystalline polymers (Makarov et al., 2014a).

\section{CALCULATION OF THE ACTIVATION ENERGY OF RELAXATION AND CREEP DEFORMATION PROCESSES OF POLYMERIC MATERIALS}

In order to verify the quantitative correspondence to these views on the curves obtained from a set of creep and relaxation of a polyester thread 83 tex., the activation energies were calculated using the well-known Arrhenius-Boltzmann formula which is given by (Demidov et al., 2006a).

$$
\begin{aligned}
& U_{\sigma}=R T \cdot\left(\ln \frac{t_{1}}{\tau_{0}}-\ln \frac{t_{1}}{\tau_{\sigma}}\right), \\
& U_{\varepsilon}=R T \cdot\left(\ln \frac{t_{1}}{\tau_{0}}-\ln \frac{t_{1}}{\tau_{\varepsilon}}\right),
\end{aligned}
$$

where $\tau_{0}$ - the parameter that has the meaning of the duration of the elementary rearrangement of 'relaxing' particles of the material $t_{1}=1$ minutes; $f_{\tau_{\sigma}}=\ln \frac{t_{1}}{\tau_{\sigma}}$ - force-time function, $\tau_{\sigma}$ delay time; $f_{\tau_{\varepsilon}}=\ln \frac{t_{1}}{\tau_{\varepsilon}}$ - deformation-time function, $\tau_{\varepsilon}$ relaxation time; $T$ - temperature ${ }^{o} \mathrm{~K}$; $R=k A, k$ - the Boltzmann constant, $A$ - the Avogadro number; $U_{\sigma}$ - activation energy as a function of stress; $U_{\varepsilon}$ - activation energy as a function of deformation.

In the calculation of the relaxation and creep activation energy of a polyester thread 83 tex., the following values were used: $R=8,31 \mathrm{~kJ} / \mathrm{mol}^{*} \operatorname{grad}$ and $\tau_{0} \cong 5 \cdot 10^{-12} \mathrm{c}$, whence it follows that $\ln \frac{t_{1}}{\tau_{0}} \cong 30$.

The calculation results are shown in Figure 1 and Figure 2. It is evident that the calculated dependencies are linear. In equations (Demidov et al., 2009)

$$
\begin{gathered}
U_{\sigma}=U_{0}-\gamma \\
U_{\varepsilon}=U_{0}-\gamma \cdot E_{\tau} \varepsilon
\end{gathered}
$$

according to Figure 1 and Figure 2, it is obtained that $U_{0}=100 \mathrm{~kJ} / \mathrm{mol}$ and $\gamma \cong 4 \cdot 10^{-22} \mathrm{~cm}^{3}$.

In the calculation of $\gamma$ according to Figure 2, the mean value of the viscoelastic modulus was used $E_{\tau}=8,5 \mathrm{GPa}$. These values correspond to the molecular mobility of the segments or the destruction of van der Waals cross-links between the side groups.

The proximity and stability of the lines obtained in Figure 1 and Figure 2 with reference to temperature changes confirms the concept validity of the micromechanism of delay or relaxation unity in the considered temperature range, as well as, the physical validity of the analogies used. In this case, it is assumed that with a change in temperature, the physical meaning of the used parameters-characteristics is preserved but their numerical values may change. 


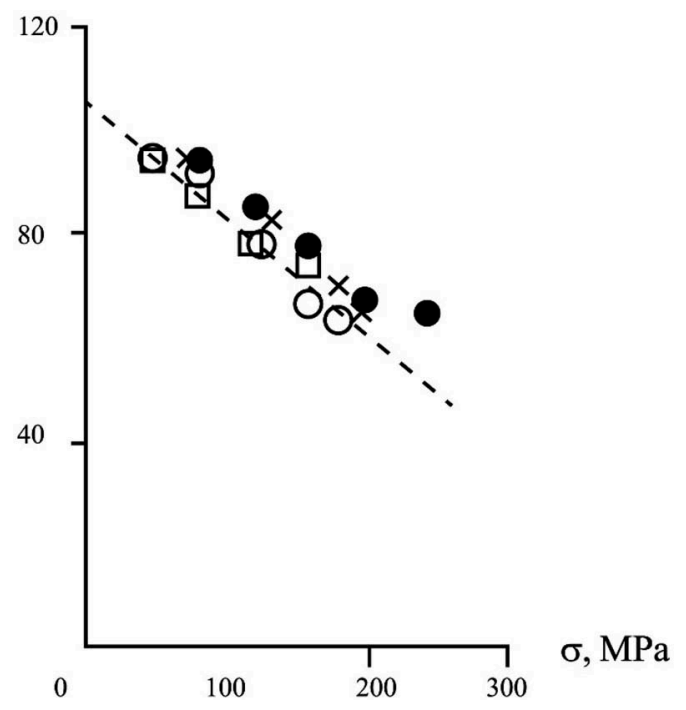

Figure 1. The dependence of activation energy on stress at temperatures $20^{\circ} \mathrm{C}(\bullet) ; 40^{\circ} \mathrm{C}(\mathrm{x}) ; 60^{\circ} \mathrm{C}(\mathrm{o})$; $80^{\circ} \mathrm{C}(\square)$ of a polyester thread 83 tex.

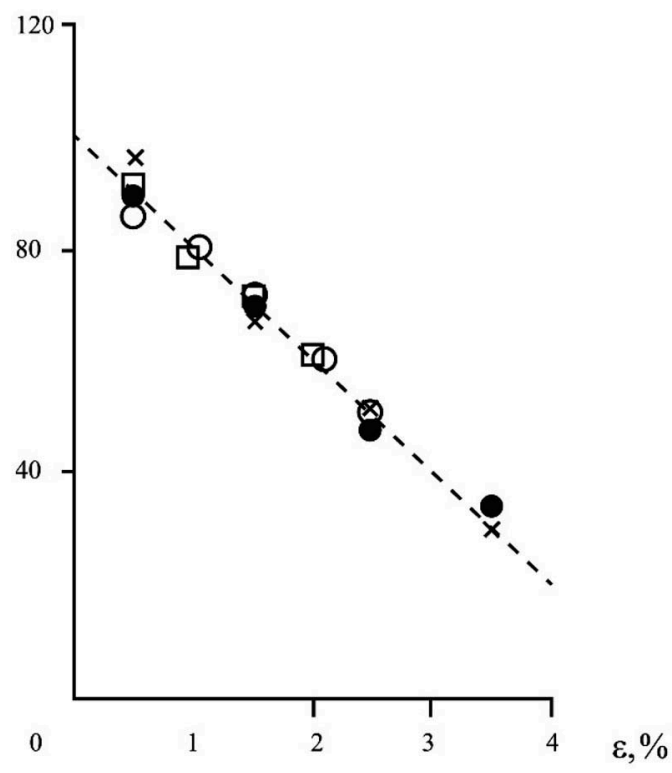

Figure 2. The dependence of the activation energy on deformation at temperatures $20^{\circ} \mathrm{C}\left(\bullet^{\circ}\right) ; 40^{\circ} \mathrm{C}(\mathrm{x})$; $60^{\circ} \mathrm{C}(\mathrm{o}) ; 80^{\circ} \mathrm{C}(\square)$ of a polyester thread 83 tex.

Consequently, in the investigated temperature range the isothermal force-time and deformation-time analogies are generalised into the temperature-force-time and temperaturedeformation-time analogies, respectively (Makarov et al., 2014b). It should be emphasised that the assumptions made in the mathematical description of the hereditary-rheological properties of polymeric materials did not affect the calculation of the activation energies of the delay times (14) and the relaxation times (15). The obtained decreasing character of the 
activation energy (16), (17) corresponds to the modern approaches to the activating character of mechanical action and the leading role of thermal fluctuations at the molecular level.

\section{CALCULATION OF THE COMPONENTS OF DEFORMATION OF POLYMERIC MATERIALS}

The process of deformation of polymeric materials at a constant speed $\dot{\varepsilon}$ at the initial stage of the stress-strain diagram (Figure 3 ) is analytically described by a phenomenological integral equation of the nonlinear-hereditary type (6) which by changing the variable $s=t-\theta$ is reduced to the form

$$
\sigma_{t}=E_{o} \varepsilon_{t}-\left(E_{o}-E_{\infty}\right) \cdot \int_{0}^{t} \varepsilon_{t-s} \cdot \varphi_{\varepsilon s}^{\prime} d s
$$

Let's take a closer look at the stress-strain diagram (Figure 3). Where $\varepsilon_{t}=\dot{\varepsilon} \cdot \mathrm{t}$ and $\sigma_{t}$ are the coordinates of a point; $\varepsilon_{t-\mathrm{s}}=\dot{\varepsilon} \cdot(\mathrm{t}-\mathrm{s})$ is the deformation under the integral sign in the formula (18).

Due to the fact that all parameters and functions included in (18) have a well-defined physical meaning, equation (18) can be considered as the mathematical model of the mechanical properties of a polymeric material with a specific spectral interpretation (Demidov et al., 2007a).

Both in the general case when $\dot{\varepsilon} \neq$ const and in the special case when $\dot{\varepsilon}=$ const, elastic $\left(\varepsilon_{t o}\right)$ and absorbed $\left(\varepsilon_{t t}\right)$ deformation components can be obtained using the formulas (Demidov et al., 2007b).

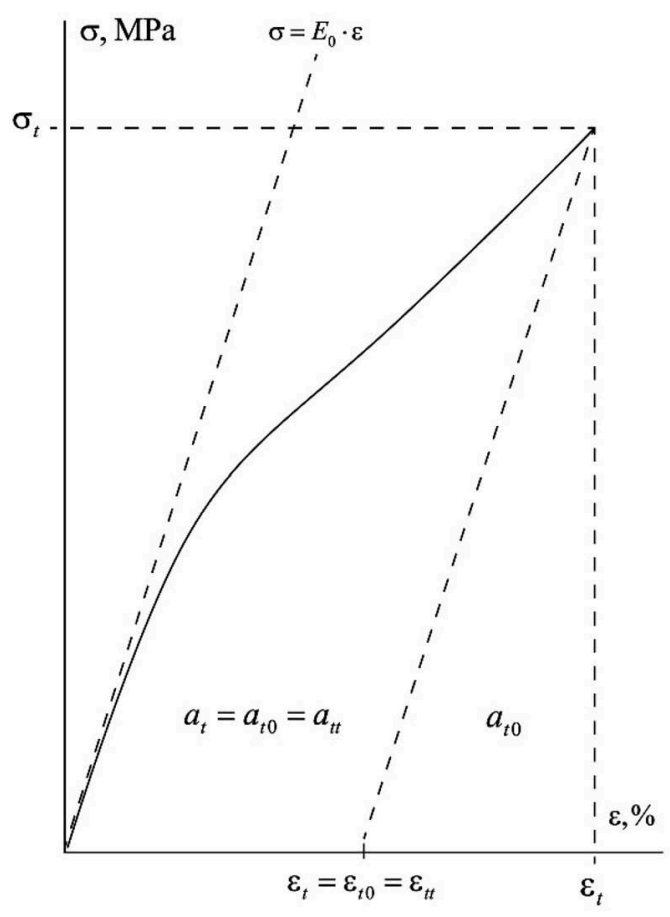

Figure 3. The decomposition scheme of the total deformation $\varepsilon_{t}$ and mechanical work $a_{t}$ of a polymer material into elastic $\left(\varepsilon_{t o}, a_{t o}\right)$ and absorbed $\left(\varepsilon_{t t}, a_{t t}\right)$ components. 


$$
\begin{gathered}
\varepsilon_{t o}=E_{o}^{-1} \sigma_{t} \\
\varepsilon_{t t}=\varepsilon_{t}-\varepsilon_{t o}
\end{gathered}
$$

or a calculated prediction based on (18) taking into account (19) and (20) (Demidov et al., 2006b).

$$
\begin{gathered}
\varepsilon_{t t}=\left(1-E_{\infty} E_{o}^{-1}\right) \int_{o}^{t} \varepsilon_{t-s} \varphi_{\varepsilon s}^{\prime} d s \\
\varepsilon_{t o}=\varepsilon_{t}-\varepsilon_{t t}
\end{gathered}
$$

Obtaining of elastic and absorbed deformation components for a polyester thread 83 tex. $T=40^{\circ} \mathrm{C}, \dot{\varepsilon}=0,083 c^{-1}$ is shown in Figure 4 .

The calculated values of the deformation components of a polyester thread 83 tex. $T=40^{\circ} \mathrm{C}$, $\dot{\varepsilon}=0,083 c^{-1}$ are given in Table 1 .

The relative fractions of elastic and absorbed deformation components are equal (Demidov et al., 2006c)

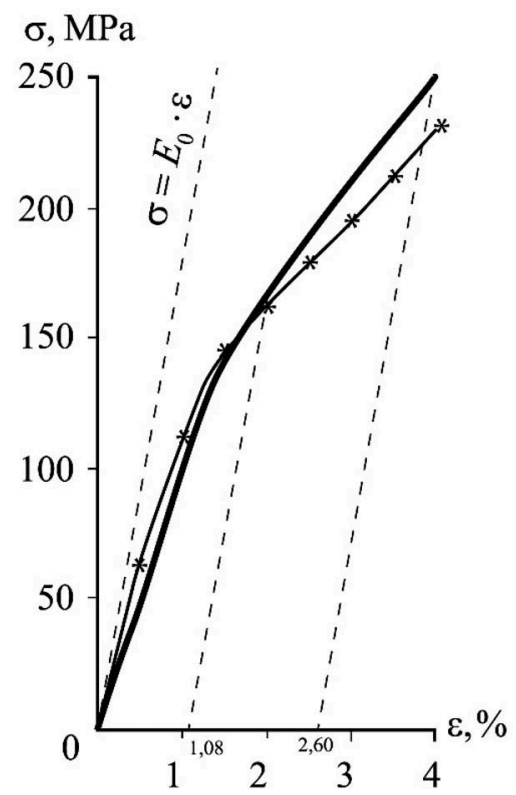

Figure 4. The stress-strain diagram of a polyester tread 83 tex., $T=40^{\circ} \mathrm{C}, \dot{\varepsilon}=0,083 c^{-1}$ (solid line experiment, - * - - calculation).

Table 1. The values of the deformation components of a polyester thread 83 tex., $T=40^{\circ} \mathrm{C}$.

\begin{tabular}{lll}
\hline$\varepsilon_{t}$ & $\varepsilon_{t o}$ & $\varepsilon_{t t}=\varepsilon_{t}-\varepsilon_{t o}$ \\
\hline 2,00 & 0,92 & 1,08 \\
4,00 & 1,40 & 2,60 \\
\hline
\end{tabular}




$$
\begin{gathered}
\varepsilon_{t o} \varepsilon_{t}^{-1}=E_{o}^{-1} \sigma_{t} \varepsilon_{t}^{-1} \\
\varepsilon_{t o} \varepsilon_{t}^{-1}=1-\left(1-E_{\infty} E_{o}^{-1}\right) \varepsilon_{t}^{-1} \int_{o}^{t} \varepsilon_{t-s} \varphi_{\varepsilon s}^{\prime} d s
\end{gathered}
$$

In the calculations using (19) - (24) the corresponding viscoelastic parameterscharacteristics are used $E_{o}, E_{\infty}, f_{\tau_{\varepsilon} \varepsilon}, A_{\varepsilon}$.

Thus, the decomposition of the total deformation into elastic and absorbed components can be carried out either using the experimental stress-strain diagram (19), (20) or by the calculated prediction (21), (22).

\section{CALCULATION OF THE ENERGY COMPONENTS OF THE DEFORMATION MECHANICAL WORK OF POLYMERIC MATERIALS}

By analogy with the method of the total deformation of polymeric materials decomposition $\varepsilon_{t}$ into elastic $\varepsilon_{t o}$ and absorbed $\varepsilon_{t t}$ components, the decomposition of the specific (per unit volume) mechanical deformation work $a_{t}$ into elastic $a_{t o}$ and absorbed $a_{t t}$ components can be considered (Demidov et al., 2006d).

For a given point of the stress-strain diagram (Figure 3) with coordinates $\varepsilon_{t}$ and $\sigma_{t}$ the specific mechanical work is calculated by the formula

$$
a_{t}=\int_{o}^{\varepsilon_{t}} \sigma_{t} d \varepsilon
$$

Taking into account (18), from (25) the prediction formula is developed (Demidov et al., 2007c).

$$
a_{t}=0,5 E_{o} \varepsilon_{t}^{2}-\dot{\varepsilon}\left(E_{o}-E_{\infty}\right) \int_{o}^{t} \int_{o}^{t} \varepsilon_{t-s} \varphi_{\varepsilon s}^{\prime} d s d t
$$

The elastic component of specific mechanical work (Stalevich et al., 2003).

$$
a_{t o}=0,5 E_{o}^{-1} \sigma_{t}^{2}
$$

and, accordingly, the elastic fraction of mechanical work $\left(a_{t o} / a_{t}\right)$ is obtained for a given point of the diagram with coordinates $\varepsilon_{t}$ and $\sigma_{t}$ or directly using the formula (25) (Makarov, 2002)

$$
\frac{a_{t o}}{a_{t}}=\frac{\sigma_{t}^{2}}{2 E_{o} \int_{o}^{\varepsilon_{t}} \sigma_{\mathrm{t}} d \varepsilon}
$$

or by the prediction using the formula (28) with the help of (18) (Stalevich et al., 2002a) 


$$
\begin{aligned}
& \frac{a_{t o}}{a_{t}}=\frac{E_{o}^{2} \varepsilon_{t}^{2}+\left(\int_{o}^{t} \varepsilon_{t-s} E_{\varepsilon s}^{\prime} d s\right)^{2}+2 \varepsilon_{t} E_{o} \int_{o}^{t} \varepsilon_{t-s} E_{\varepsilon s}^{\prime} d s}{E_{o}^{2} \varepsilon_{t}^{2}+2 \dot{\varepsilon} E_{o} \int_{o}^{t} \int_{o}^{t} \varepsilon_{t-s} E_{{ }_{\varepsilon s}} d s d t}= \\
& =\frac{\varepsilon_{t}^{2}+(1-c)^{2}\left(\int_{o}^{t} \varepsilon_{t-s} \phi_{\varepsilon s}^{\prime} d s\right)^{2}+2 \varepsilon_{t}(1-c) \int_{o}^{t} \varepsilon_{t-s} \phi^{\prime}{ }_{\varepsilon s} d s}{\varepsilon_{t}^{2}+2 \dot{\varepsilon}(1-c) \int_{o}^{t} \int_{o}^{t} \varepsilon_{t-s} \phi^{\prime}{ }_{\varepsilon s} d s d t}
\end{aligned}
$$

where $c=\frac{\mathrm{E}_{\infty}}{E_{o}}$.

The absorbed part of the specific mechanical work (Stalevich et al., 2002b)

$$
a_{t t}=a_{t}-a_{t o}
$$

or its relative part

$$
\frac{a_{t t}}{a_{t}}=1-\frac{a_{t o}}{a_{t}}
$$

are also obtained in any of the two mentioned ways (Stalevich et al., 2000).

For example, the values of the specific work and its elastic and absorbed components for a polyester thread 83 tex., $t=40^{\circ} \mathrm{C}$, at a deformation speed $\dot{\varepsilon}=0,083 \mathrm{c}^{-1}$ are given in Table 2 .

The calculation results of the fraction of elastic component of mechanical work $\frac{a_{t o}}{a_{t}}$ depending on the deformation $\varepsilon$ according to (28) - (31) are shown in Figure 5.

As it is evident from the graph (Figure 5), the fraction of the component $\mathrm{a}_{\mathrm{tt}}$ in mechanical work increases, the fraction of the component $a_{t o}$ decreases with increasing deformation $\varepsilon$ (Makarov et al., 2014c). This means that in order to return to its original state, according to the law of conservation of energy, the material needs to transfer from the external environment the more (in percentage) energy, the more it is deformed. On the other hand, this fact indicates the emerging role of the viscoelastic factor with the increase of deformation (Potapov et al., 2018).

As the result, the methods for obtaining the elastic component of mechanical work from the stress-strain diagrams or using the calculated prediction at the stage of nondestructive mechanical action are proposed (Blinov te al., 2018). The proximity of elastic components values obtained from the measured or predicted stress-strain diagram confirms the quite satisfactory reliability of physical and mechanical properties modelling of a thread in the form of a nonlinear hereditary equation (18) (Vasil'eva et al., 2016).

Table 2. The values of the specific deformation work $\left(a_{t}\right)$, its elastic $\left(a_{t o}\right)$ and absorbed $\left(a_{t t}\right)$ components for the deformation values $\varepsilon_{t}$ of a polyester thread 83 tex., $t=40^{\circ} \mathrm{C}$ at a deformation speed $\underline{\varepsilon}=0,083 c^{-1}$.

\begin{tabular}{llll}
\hline$\varepsilon_{t}, \%$ & $a_{t}, \mathrm{MPa}$ & $a_{t o}, \mathrm{MPa}$ & $a_{t t}, \mathrm{MPa}$ \\
\hline 2,00 & 1,86 & 0,76 & 1,10 \\
4,00 & 5,42 & 1,75 & 3,67 \\
\hline
\end{tabular}




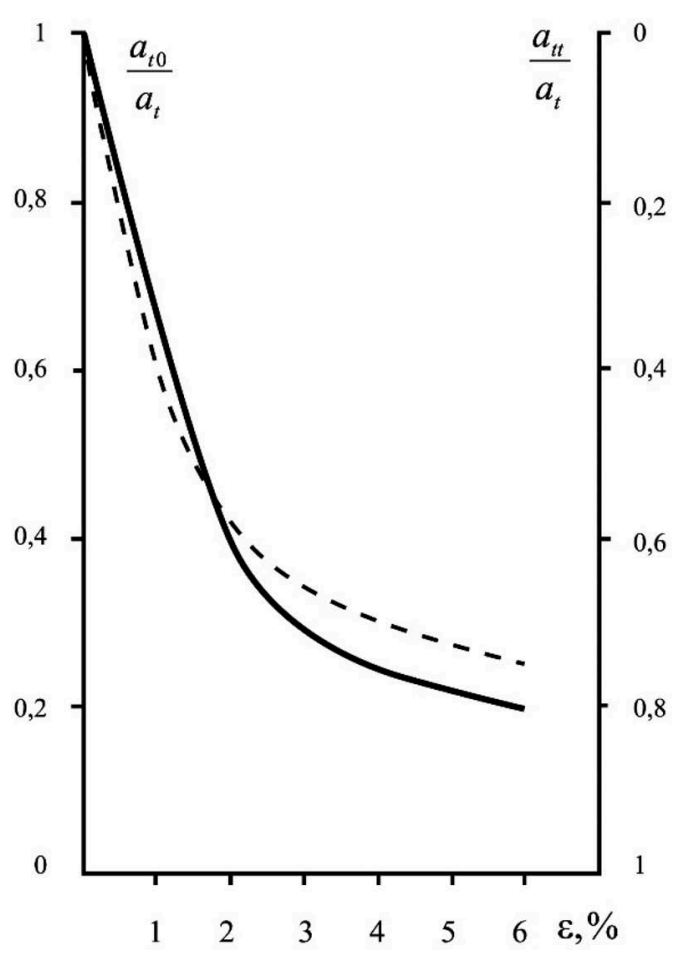

Figure 5. The fraction of elastic component $\frac{a_{t o}}{a_{t}}$ and absorbed component $\frac{a_{t t}}{a_{t}}$ of mechanical work during deformation of a polyester thread 83 tex., $T=40^{\circ} \mathrm{C}$ depending on the deformation $\varepsilon, \%$ (solid line - experiment, - - - calculation).

\section{CONCLUSION}

In sum, the energy characteristics of relaxation and creep processes were considered. Specifically, the methods for decomposition of the deformation mechanical work into two elasticreversible and viscoelastic-plastic components are developed. The proximity of the values of elastic components obtained from the measured and predicted stress-strain diagram confirms the reliability of the mechanical properties modelling of a polymeric material in the form of a nonlinear hereditary governing equation.

The methods for decomposition of deformation of polymeric materials into their components: elastic deformation, highly elastic deformation and plastic deformation allows to better understand the nature of deformation processes. Taking into account the plastic component of deformation helps to improve the accuracy and, consequently, the reliability of predicting both simple and complex nonlinear hereditary viscoelastic processes.

The proximity of the energy parameters calculated from the delay times and from the relaxation times, their invariability in the temperature range, and the decreasing nature of the activation energy confirm the thermofluctuation interpretation of the viscoelastic nonlinearity of the delay and relaxation kernels at the level of intermolecular interaction and internal rotation in chemical bonds.

The analysis of the activation parameters calculated from the obtained delay times and relaxation times confirms the consistency of the hypothesis about the activating nature of mechanical action at the level of intermolecular interactions and internal rotation. It also confirms the consistency of the thermofluctuation interpretation of viscoelastic nonlinearity of the used delay and relaxation kernels. This substantiates the proposed methods for the analytical description of the hereditary rheological properties of polymeric materials. 


\section{FUTURE RESEARCH AND ACKNOWLEDGEMENTS}

The study was funded within the framework of the state assignment of the Ministry of Science and Higher Education of the Russian Federation, Project No. FSEZ-2020-0005.

\section{REFERENCES}

Blinov, P.A., Dvoynikov, M.V. (2018) Rheological and Filtration Parameters of the Polymer Salt Drilling Fluids Based on Xanthan Gum. Journal of Engineering and Applied Sciences, 13: 5661-5664. DOI: $10.36478 / 2018.5661 .5664$

Demidov, A.V., Makarov, A.G., Stalevich, A.M. (2006a) The criteria of optimal selection of mathematical model of textile materials viscoelasticity. Izvestiya Vysshikh Uchebnykh Zavedenii, Seriya Teknologiya Tekstil'noi Promyshlennosti, Vol. 293, No 5, pp. 21-25. eid=2-s2.0-34247548784

Demidov, A.V., Makarov, A.G., Stalevich, A.M., Petrova, L.N., Chelishev, A.M. (2006b) Research of changes of deformation properties of polyester threads depending on twist amount. Izvestiya Vysshikh Uchebnykh Zavedenii, Seriya Teknologiya Tekstil'noi Promyshlennosti, Vol. 292, No 4, pp. 9-13. eid=2-s2.0-33845499474

Demidov, A.V., Makarov, A.G., Stalevich, A.M. (2006c) Methods of computer analysis of viscoelasticity of technical materials. Izvestiya Vysshikh Uchebnykh Zavedenii, Seriya Teknologiya Tekstil'noi Promyshlennosti, Vol. 291, No 3, pp. 13-17. eid=2-s2.0-37849188658

Demidov, A.V., Makarov, A.G., Stalevich, A.M. (2006d) Definition of the mechanical characteristics of textile stuffs at variable temperature. Izvestiya Vysshikh Uchebnykh Zavedenii, Seriya Teknologiya Tekstil'noi Promyshlennosti, Vol. 294, No 6, pp. 15-18. eid=2-s2.0-34250009041

Demidov, A.V., Makarov, A.G., Stalevich, A.M. (2007a) Definition of the computer forecasting trends of deformation properties of textile stuffs. Izvestiya Vysshikh Uchebnykh Zavedenii, Seriya Teknologiya Tekstil'noi Promyshlennosti, Vol. 297, No 2, pp. 14-17. eid=2-s2.0-38849203122

Demidov, A.V., Makarov, A.G., Stalevich, A.M. (2007b) System analysis of viscoelasticity of textile stuffs. Izvestiya Vysshikh Uchebnykh Zavedenii, Seriya Teknologiya Tekstil'noi Promyshlennosti, Vol. 298, No 3, pp. 11-14. eid=2-s2.0-34648822922

Demidov, A.V., Makarov, A.G., Stalevich, A.M. (2007c) Predicting the nonlinear hereditary viscoelasticity of polymers. Journal of Applied Mechanics and Technical Physics, Vol. 48, No 6, pp. 897-904. DOI: $10.1007 / \mathrm{s} 10808-007-0114-8$

Demidov, A.V., Makarov, A.G., Stalevich, A.M. (2009) A version of modeling of nonlinear-hereditary viscoelasticity of polymer materials. Mechanics of Solids, Vol. 44, No 1, pp. 122-130. DOI: 10.3103/ S0025654409010130

Demidov, A.V., Makarov, A.G., Pereborova, N.V., Egorova, M.A. (2017) Forecasting of deformation-relaxation properties of poly amide fabric used to make the canopy. Izvestiya Vysshikh Uchebnykh Zavedenii, Seriya Teknologiya Tekstil'noi Promyshlennosti, Vol. 367, No 1, pp. 250-258. eid=2-s2.0-85033239149

Gorshkov, A.S., Makarov, A.G., Romanova, A.A., Rymkevich, P.P. (2013) Modelling of directed polymers deformation processes based on the description of the kinetics of supramolecular structures separated by energy barriers. Magazine of Civil Engineering, Vol. 44, No 9, pp. 76-83+103-104. DOI: 10.5862/MCE.44.10

Makarov, A.G. (2002) Determining the analytical correlation between the standardized nuclei of relaxation and creep in textile materials. Izvestiya Vysshikh Uchebnykh Zavedenii, Seriya Teknologiya Tekstil'noi Promyshlennosti, Vol. 266, No 2, pp. 13-17. eid=2-s2.0-0036931214

Makarov, A.G., Pereborova, N.V., Egorova, M.A., Wagner, V.I. (2014a) Modeling and forecasting viscoelastic properties of textile materials with a complex structure. Izvestiya Vysshikh Uchebnykh Zavedenii, Seriya Teknologiya Tekstil'noi Promyshlennosti, Vol. 354, No 6, pp. 120-124. eid=2-s2.0 $-84937439497$

Makarov, A.G., Pereborova, N.V., Egorova, M.A., Wagner, M.A. (2014b) Ways of modeling deformation and relaxation properties of textile materials with a complex structure. Izvestiya Vysshikh Uchebnykh Zavedenii, Seriya Teknologiya Tekstil'noi Promyshlennosti, Vol. 351, No 3, pp. 110-115. eid=2-s2 $.0-84937410003$

Makarov, A.G., Pereborova, N.V., Wagner, V.I., Rymkevich, P.P., Gorshkov, A.S. (2014c) The Basis of Spectral-Temporal Analysis of Relaxation and Deformation Properties of Polymeric Materials in Textile and Ligt Industry. Izvestiya Vysshikh Uchebnykh Zavedenii, Seriya Teknologiya Legkoi Promyshlennosti. Vol. 23, No 1. pp. 24-29. 
Makarov, A.G., Slutsker, G.Y., Drobotun, N.V. (2015) Creep and fracture kinetics of polymers. Technical Physics, Vol. 60, No 2, pp. 240-245. DOI: 10.1134/S1063784215020152

Makarov, A.G., Demidov, A.V., Pereborova, N.V., Egorova, M.A. (2015a) Modeling and prediction of estimated relaxation and deformation properties of the polymer parachute line. Izvestiya Vysshikh Uchebnykh Zavedenii, Seriya Teknologiya Tekstil'noi Promyshlennosti, Vol. 360, No 6, pp. 194-205. eid=2-s2.0-84976560627

Makarov, A.G., Pereborova, N.V., Wagner, V.I., Vasileva, E.K. (2015b) Development of methodology for the comparative analysis of deformation and relaxation properties of aramid yarns and textile materials based on them. Izvestiya Vysshikh Uchebnykh Zavedenii, Seriya Teknologiya Tekstil'noi Promyshlennosti, Vol. 359, No 5, pp. 48-58. eid=2-s2.0-84971636036

Makarov, A.G., Slutsker, G.Y., Gofman, I.V., Vasil'eva, V.V. (2016) Initial stage of stress relaxation in oriented polymers. Physics of the Solid State, Vol. 58, No 4, pp. 840-846. DOI: 10.1134/ S1063783416040132

Makarov, A.G., Pereborova, N.V., Egorova, M.A., Egorov, I.M. (2017a) Quality analysis of deformation-relaxation properties of aramid cords mountain rescue appointments. Izvestiya Vysshikh Uchebnykh Zavedenii, Seriya Teknologiya Tekstil'noi Promyshlennosti, Vol. 368, No 2, pp. 309-313. eid=2-s2.0-85035207042

Makarov, A.G., Pereborova, N.V., Egorova, M.A., Egorov, I.M. (2017b) Mathematical modeling of deformation-relaxation processes polymeric materials in conditions of variable temperatures. Izvestiya Vysshikh Uchebnykh Zavedenii, Seriya Teknologiya Tekstil'noi Promyshlennosti, Vol. 370, No 4, pp. 287-292. eid=2-s2.0-85057142312

Makarov, A.G., Pereborova, N.V., Kozlov, A.A., Shvankin, A.M. (2018a) Computer-Assisted Prediction and Qualitative Analysis for Polymer Parachute Cords Fibre Chemistry, Vol. 50, No. 3, pp. 239-242. DOI 10.1007/s10692-018-9968-1

Makarov, A.G., Pereborova, N.V., Vagner, V.I., Egorova, M.A., Klimova, N.S. (2018b) Spectral Analysis of Viscoelastic Creep of Geotextiles. Fibrie Chemistry, Vol. 50, No 4, pp. 378-382. DOI 10.1007/ s10692-019-09993-4

Pereborova, N.V., Demidov, A.V., Makarov, A.G., Klimova, N.S. (2018a) Modeling of DeformationRelaxation Processes of Aramid Textile Materials - the Foundation for Analyzing Their Operational Properties. Fibre Chemistry, Vol. 50, No. 2, pp. 104-107. DOI 10.1007/s10692-018-9941-z

Pereborova, N.V., Makarov, A.G., Egorova, M.A., Kozlov, A.A., Konovalov, A.S. (2018b) Methods of simulation and comparative analysis of shadow and deformation-reducing properties of aramide textile materials. Izvestiya Vysshikh Uchebnykh Zavedenii, Seriya Teknologiya Tekstil'noi Promyshlennosti, Vol. 375, No 3, pp. 253-257. eid=2-s2.0-85059766891

Pereborova N.V., Makarov A.G., Kozlov A.A., Vasil'eva E.K. (2018c) Development of Integral Optimality Criteria for Mathematical Modeling of Relaxation/Recovery Processes in Polymer Textile Materials. Fibrie Chemistry, Vol. 50, No 4, pp. 306-309. DOI 10.1007/s10692-019-09981-8

Pereborova, N.V., Makarov, A.G., Egorova, M.A., Klimova, N.S. (2018d) Methods of increasing the competitiveness of domestic aramid textile materials based on complex analysis of their functional properties. Izvestiya Vysshikh Uchebnykh Zavedenii, Seriya Teknologiya Tekstil'noi Promyshlennosti, Vol. 378, No 6, pp. 267-272. eid=2-s2.0-85072335464

Pereborova, N.V., Demidov, A.V., Makarov, A.G., Klimova, N.S., Vasileva, E.K. (2018e) Methods of mathematical modeling and qualitative analysis of relaxation-deformation processes of aramide textile materials. Izvestiya Vysshikh Uchebnykh Zavedenii, Seriya Teknologiya Tekstil'noi Promyshlennosti, Vol. 374, No 2, pp. 251-255. eid=2-s2.0-85056451197

Pereborova, N.V., Makarov, A.G., Vasil'eva, E.K., Shvankin, A.M., Egorov, I.M. (2019a) Mathematical Modeling and Computed Prediction of Viscoelastic Creep in Geotextile Nonwoven Fabrics. Fibre Chemistry, Vol. 50, No 6, pp. 487-490. DOI 10.1007/s10692-019-10015-6

Pereborova, N.V., Makarov, A.G., Egorova, M.A., Kozlov, A.A. (2019b) Mathematical Modeling and Comparative Analysis of Deformation/Recovery Properties and Shrinkage of Aramid Textile Materials. Fibre Chemistry, Vol. 50, No 5, pp. 468-472. DOI 10.1007/s10692-019-10010-x

Pereborova, N.V., Makarov, A.G., Egorova, M.A., Klimova, N.S. (2019c) Improving the Competitiveness of Aramid Textile Materials Based on Mathematical Modeling and Analysis of Their Performance Properties. Fibre Chemistry, Vol. 50, No 6, pp. 569-572. DOI 10.1007/s10692-019-10030-7

Pereborova, N.V., Makarov, A.G., Shvankin, A.M., Egorova, M.A., Abramova, I.V. (2020a) Modeling and Qualitative Analysis of Creep Processes of Geotextile Nonwovens -A Foundation for Enhancing their Competitiveness. Fibre Chemistry, Vol. 51, No. 5, pp. 397-400. DOI 10.1007/s10692-020-10119-4

Pereborova, N.V., Makarov, A.G., Shvankin, A.M., Egorova, M.A., Korobovtseva, A.A. (2020b) Predicting Creep and Deformation and Recovery Processes of Geotextile Nonwovens. Fibre Chemistry, Vol. 51, No. 5, pp. 401-403. DOI 10.1007/s10692-020-10120-x 
Pereborova, N.V., Makarov, A.G.,Egorova, M.A., Egorov, I.M. (2020c) Methods of Modeling and Computer-Aided Prediction of Relaxation of Medical-Purpose Textile Elastomers. Fibre Chemistry, Vol. 51, No. 6, pp. 467-470. DOI 10.1007/s10692-020-10136-3

Pereborova, N.V., Makarov, A.G.,Egorova, M.A., Egorov, I.M. (2020d) Methods modeling and Computer-Aided Prediction of Strain and Relaxation Processes of Medical-Purpose Textile Elastomers. Fibre Chemistry, Vol. 51, No. 6, pp. 471-474. DOI 10.1007/s10692-020-10137-2

Potapov, A., Makhov, V. (2018) Methods for Nondestructive Testing and Diagnostics of Durability of Articles Made of Polymer Composite Materials. Russian Journal of Nondestructive Testing. 54. 151-163. 10.1134/S1061830918030087.

Rymkevich, P.P., Romanova, A.A., Golovina, V.V., Makarov, A.G. (2013) The energy barriers model for the physical description of the viscoelasticity of synthetic polymers: Application to the uniaxial orientational drawing of polyamide films. Journal of Macromolecular Science, Part B: Physics, Vol. 52, No 12, pp. 1829-1847. DOI: 10.1080/00222348.2013.808906

Stalevich, A.M., Makarov, A.G. (2000) Determining the inherent viscoelastic relaxation spectrum for synthetic filaments. Izvestiya Vysshikh Uchebnykh Zavedenii, Seriya Teknologiya Tekstil'noi Promyshlennosti, Vol. 255, No 3, pp. 8-12. eid=2-s2.0-0034436083

Stalevich, A.M., Makarov, A.G. (2002a) Forecasting the deformation recovery process and the reverse relaxation in polymer materials. Izvestiya Vysshikh Uchebnykh Zavedenii, Seriya Teknologiya Tekstil'noi Promyshlennosti, Vol. 267, No 3, pp. 10-13. eid=2-s2.0-0038128574

Stalevich, A.M., Makarov, A.G., Saidov, E.D. (2002b) Elastic components in the stress/strain curve for a synthetic fibre yarn. Izvestiya Vysshikh Uchebnykh Zavedenii, Seriya Teknologiya Tekstil'noi Promyshlennost $i$, Vol. 268, No 4-5, pp. 15-18. eid=2-s2.0-0037742684

Stalevich, A.M., Makarov, A.G., Saidov, E.D. (2003) Relaxation spectrometry of synthetic yarns. Izvestiya Vysshikh Uchebnykh Zavedenii, Seriya Teknologiya Tekstil'noi Promyshlennosti, Vol. 270, No 1, pp. 16-22. eid=2-s2.0-2642532049

Vasil'eva, M.A., Feit, S. (2016) Investigation of polymer material of the working camera-channel of the magnetic pumps for heavy oil. Journal of Mining Institute, 221, p. 651. DOI: 10.18454/pmi.2016.5.651 